\title{
A nomogram for B.T.P.S.-volume corrections in pulmonary ventilation tests
}

\author{
J. G. M A CKENZIE \\ From the Pathology Department and Pulmonary Investigation Unit, Prince Henry's Hospttal, \\ Melbourne, Australia
}

The conversion of a spirometer tracing into a volume of gas corrected to body temperature and pressure saturated with water vapour (B.T.P.S.volume) involves: (a) a factor to convert centimetres of tracing height to millilitres of gas at the existing (or 'ambient') temperature and pressure saturated with water vapour (A.T.P.S.-volume), this factor being $\mathbf{3 0 0}$ for the Godart apparatus in use in this Unit, since $1 \mathrm{~cm}$. is equivalent to $300 \mathrm{ml}$. of gas; (b) conversion of A.T.P.S.-volume to B.T.P.S.-volume by the application of Boyle's and Charles' laws and the known values of water vapour partial pressure at different temperatures.

Detailed investigation of a single patient requires that these steps should be repeated many times. Hence a welcome contribution was the provision of a set of factors for the second calculation in the range $20-37^{\circ} \mathrm{C}$. (Comroe, Forster, Dubois, Briscoe, and Carlsen, 1962), barometric pressure changes between 750 and $770 \mathrm{~mm}$. $\mathrm{Hg}$ having been shown to be insignificant. These factors are therefore primarily dependent upon laboratory temperature.

This paper extends the range of the Comroe factors to $15-40^{\circ} \mathrm{C}$., as these extremes have occasionally been required, and presents an easily constructed nomogram for the complete calculation.

THE B.T.P.S.-VOLUME CORRECTION FACTORS

Applying the gas laws, Comroe's factors were obtained from the equation:

$$
\begin{aligned}
\text { Correction factor } & =\left(\frac{273+37}{273+T}\right) \times\left(\frac{760-P}{760-47 \cdot 1}\right) \\
& =0.435\left(\frac{760-P}{273+T}\right)
\end{aligned}
$$

where $\mathrm{T}^{\circ} \mathrm{C}$. is the laboratory temperature, and $\mathbf{P ~} \mathbf{m m}$. $\mathbf{H g}$ is the partial pressure of water vapour at $\mathbf{T}^{\circ} \mathrm{C}$.
The Table shows the B.T.P.S.-volume correction factors from 15 to $40^{\circ} \mathrm{C}$., the $20-37^{\circ} \mathrm{C}$. range having been derived from Comroe et al. (1962).

\begin{tabular}{|c|c|c|}
\hline $\begin{array}{l}\text { Temperature } \\
\left({ }^{\circ} \mathrm{C} .\right)\end{array}$ & $\begin{array}{l}\text { Partial } \\
\text { Pressure of } \\
\text { Water Vapour } \\
(\mathrm{mm} . \mathrm{Hg})\end{array}$ & $\begin{array}{l}\text { B.T.P.S-volume } \\
\text { Correction } \\
\text { Factor }\end{array}$ \\
\hline $\begin{array}{l}15 \\
16 \\
17 \\
18 \\
19 \\
20 \\
21 \\
22 \\
23 \\
24 \\
25 \\
26 \\
27 \\
28 \\
29 \\
30 \\
31 \\
32 \\
33 \\
34 \\
35 \\
36 \\
37 \\
38 \\
39 \\
40\end{array}$ & 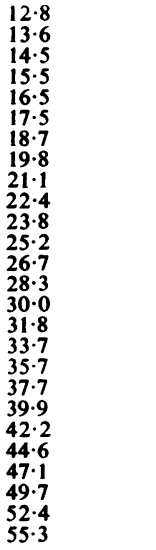 & $\begin{array}{l}1.128 \\
1.123 \\
1.118 \\
1.113 \\
1.108 \\
1.102 \\
1.096 \\
1.091 \\
1.085 \\
1.080 \\
1.075 \\
1.069 \\
1.063 \\
1.057 \\
1.051 \\
1.045 \\
1.039 \\
1.032 \\
1.026 \\
1.020 \\
1.014 \\
1.007 \\
1.000 \\
0.994 \\
0.987 \\
0.980\end{array}$ \\
\hline
\end{tabular}

T A B L E

THE B.T.P.S.-VOLUME CORRECTION NOMOGRAM

Using the full range of factors, a nomogram has been constructed which enables B.T.P.S.-volumes to be obtained with a precision of $10 \mathrm{ml}$. in the range $0-8,000 \mathrm{ml}$. (Figure).

In this Unit an enlarged version of the nomogram has been firmly pasted on to plyboard and lacquered. Readings are taken by means of a Perspex strip, $\frac{1}{8}$ in. thick, with a single midline ruling.

Since laboratory temperature usually remains constant for a particular test session, it is convenient to fix the ruling at this reading. This is simply done by drilling fine holes through the degree points on the temperature scale, and fixing a suitable pin through the hair-line at one end of 358 


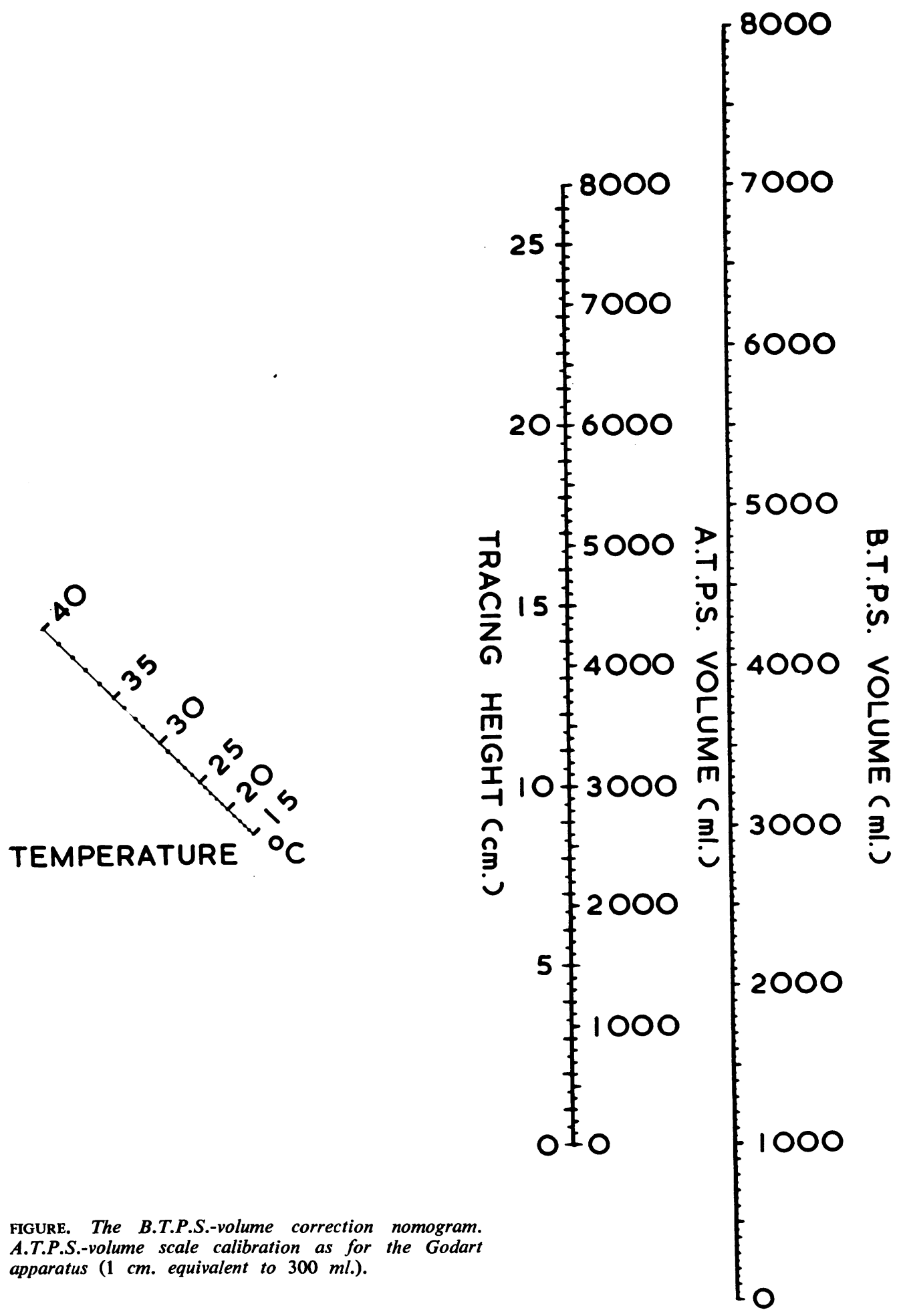


the Perspex strip. Speed and ease of operation of the nomogram are then greatly improved.

With the temperature point fixed, the ruler is rotated to the value of the tracing height measurement (centre scale) and the corresponding B.T.P.S.volume read off the right-hand scale. A.T.P.S.volumes are scaled alongside tracing height, should these be required. For apparatus where the relation of $1 \mathrm{~cm}$. tracing height: $300 \mathrm{ml}$. A.T.P.S.-volume does not apply, only the tracing height scale need be changed, since the inter-relations of temperature, A.T.P.S.-volume, and B.T.P.S.-volume remain the same.

A convenient size for a working nomogram has been found to be that with a B.T.P.S.-volume scale $16 \mathrm{in}$. in length, when $0.1 \mathrm{in}$. corresponds to $50 \mathrm{ml}$. Such a nomogram requires a 12 -inch ruler.

\section{SUMMARY}

In pulmonary function tests repetitive calculations are required to convert the height of the spirometer tracing in centimetres into gas volume, and then to apply temperature and pressure corrections. For some time, a range of factors (Comroe) has been available to assist in the second of these calculations.

This paper presents an easily constructed nomogram which performs the complete conversion of centimetres of spirometer tracing height to millilitres of gas volume, corrected to body temperature and pressure saturated with water vapour, with a precision of $10 \mathrm{ml}$. over the range $0-8,000 \mathrm{ml}$., for temperatures between 15 and $40^{\circ} \mathrm{C}$.

I wish to thank Miss Gillian Robertson and the Photographic Department of St. Mary's Hospital Medical School, London, for their assistance in the preparation of the nomogram for publication.

This paper was written during the tenure of a Nuffield Dominion Travelling Fellowship in the United Kingdom.

\section{REFERENCE}

Comroe, J. H., Forster, R. E., Dubois, A. B., Briscoe, W. A., and Carlsen, E. (1962). The Lung: Clinical Physiology and Pulmonary Function Tests 2nd ed., p. 334. Year Book Publ., Chicago. 